\title{
Chitosan-cellulose particles as delivery vehicles for limonene fragrance
}

\author{
Sofia Lopes $^{\mathrm{a}, 1}$, Catherine Afonso ${ }^{\mathrm{b}, 1}$, Isabel Fernandes ${ }^{\mathrm{c}, \mathrm{d}}$, Maria-Filomena Barreiro ${ }^{\mathrm{c}, \mathrm{d}}$, \\ Patrícia Costa $^{\mathrm{a}, *}$, Alírio E. Rodrigues ${ }^{\mathrm{a}}$ \\ ${ }^{a}$ Laboratory of Separation and Reaction Engineering - Laboratory of Catalysis and Materials (LSER-LCM), Faculdade de Engenharia, Universidade do Porto, Rua Dr. \\ Roberto Frias $s / n, 4200-465$ Porto, Portugal \\ ${ }^{\mathrm{b}}$ University of Montpellier, France \\ ${ }^{\mathrm{c}}$ Laboratory of Separation and Reaction Engineering - Laboratory of Catalysis and Materials (LSER-LCM), Instituto Politécnico de Bragança, Campus de Santa Apolónia, \\ 5301-857 Bragança, Portugal \\ ${ }^{\mathrm{d}}$ Centro de Investigação de Montanha (CIMO), Instituto Politécnico de Bragança, Campus de Santa Apolónia, 5301-857 Bragança, Portugal
}

\section{A R T I C L E I N F O}

\section{Keywords:}

Cellulose

Dissolution

Chitosan

Encapsulation

Limonene

\begin{abstract}
A B S T R A C T
This study proposes the use of chitosan-cellulose particles to encapsulate limonene, a fragrant component widely used in the flavor and fragrance industries. As cellulose possesses a stiff molecular structure due to the threedimensional arrangement of hydrogen bonded hydroxyls, its dissolution is difficult to achieve. To surpass this constraint, and solubilize cellulose, $\mathrm{LiOH} /$ urea/water systems were tested using different freezing temperatures and number of freezing/thawing/stirring cycles. Then, chitosan-cellulose composite particles were produced and characterized by Scanning Electron Microscopy (SEM) to assess morphology and size, and by Fourier Transform Infrared Spectroscopy (FTIR) and Thermogravimetric Analysis (TGA) to access chitosan-cellulose molecular interactions. The release behaviour of limonene from the chitosan-cellulose particles was studied by gas chromatography (GC). The obtained particles presented an average diameter ranging from 1 to $2 \mathrm{~mm}$ and spherical shape, characteristics very similar to the corresponding empty cellulose-chitosan composite particles. A good affinity was found between the two biopolymers, cellulose and chitosan. The achieved encapsulation efficiency of limonene was $51.29 \%$, and the produced particles demonstrated a burst release of limonene in the first $24 \mathrm{~h}$, followed by a decrease over $162 \mathrm{~h}$. Based on the achieved results this system seems favourable for applications requiring preservation of sensory qualities and prolonged release of fragrances.
\end{abstract}

\section{Introduction}

Fragrances are strong-smelling organic compounds, which surround us every day and everywhere. They are used in different perfumed products, including toiletries and household products (Fortineau, 2004; Bauer et al., 2006). However, fragrances are complex mixtures of volatile and labile substances with different reactive functional groups, whose sensory quality can be modified by environmental factors such as temperature, moisture and light (Zhu et al., 2012; Liao et al., 2016), as well as by reactions occurring during product formulation processes. As an attempt to preserve the sensory quality, and to prolong the longevity of fragrances, researchers have been proposing different approaches, including encapsulation (Hosseinkhani et al., 2015). Encapsulation is defined as a process where the capture of a compound, or various compounds, into a coating material occurs (Pena et al., 2012). Such compounds, commonly referred as core materials, are coated with one or more polymeric materials or incorporated into a homogeneous or heterogeneous matrix, in order to form microcapsules or microspheres, respectively (Estevinho et al., 2013). The morphology of the microcapsules, size and shape varies with the rigidity of the coating layer, the type of core material and the preparation method (Estevinho et al., 2013; Tekin et al., 2013). The diameter of the microcapsules usually ranges from 1 to $1000 \mu \mathrm{m}$; below $1 \mu \mathrm{m}$, they are called nanocapsules and over $1000 \mu \mathrm{m}$, macrocapsules (Peña et al., 2008).

There is a great variety of synthetic and natural polymers that can be used as shell materials for microcapsules. In the particular case of flavor and fragrance industries the shell material is typically composed of carbohydrates, cellulose, gums, lipids and proteins (Zhu et al., 2012), being its selection based on the physical and chemical properties of the core material, the applied method for the formation of the microcapsules, final application, as well as processing and economic factors (Estevinho et al., 2013; Oliveira, 2015). Furthermore, the shell material

\footnotetext{
* Corresponding author.

E-mail address: patriciasc@fe.up.pt (P. Costa).

${ }^{1}$ Authors contributed equally to this work.
} 
must have no reactivity with the core material, present low viscosity at high concentration, protect the active ingredient against external factors, and ensure good emulsion-stabilization properties (Zhu et al., 2012). Over the years, different studies have been carried out using chitosan, cellulose, including cellulose derivatives, as composite materials (Table 1) (Yang et al., 2016).

Chitosan, the deacetylated form of the polysaccharide chitin, is a biopolymer with a structure composed of D-glucosamine and $N$-acetyl-Dglucosamine units linked by $\beta(1-4)$-glycosidic bonds (Xiao et al., 2014). It is mainly found in the exoskeleton of crustaceans and it emerges as the second most abundant polysaccharide in nature (Alonso et al., 2009). Chitosan has received much attention due to its non-toxicity, wide versatility of applications, biocompatibility, antibacterial properties, abundance, gel-forming properties and hydrophilicity (Alonso et al., 2009; Souza et al., 2014). This polycationic polymer is considered as an inexpensive product and, as it possesses reactive amino functional groups, it has the potential to be used in many different areas such as biotechnology, cosmetics, food, pharmaceuticals and as carriers to release active compounds (Estevinho et al., 2013; Souza et al., 2014). Another polymer of great importance in the area of microencapsulation is cellulose and its derivatives such as ethylcellulose (Carvalho et al., 2015; Martins et al., 2014). Cellulose, isolated from plant tissues for the first time in 1838 by the French chemist Payen (Olivera et al., 2016), is a linear homopolymer composed of D-anhydroglucopyranose units, which are connected by $\beta(1-4)$-glycosidic bonds (Alves, 2015). Cellulose is the most abundant polymer in the world comprising unique properties such as the strong mechanical strength, biocompatibility and thermal stability (Duarte, 2014; Yang et al., 2016). Furthermore, it is natural, renewable, environmentally benign, cost-efficient and non-toxic (Olivera et al., 2016). It finds applications in the form of natural textile fibres or in the form of panels and paper. Native cellulose is also a starting material for subsequent chemical modifications aiming at producing a variety of cellulose derivatives with application in food, cosmetic, detergents, textile and pharmaceutical areas (Alves, 2015). Cellulose is a very polar molecule, with a high number of hydroxyl groups (Lindman et al., 2010). However, the close chain packing through numerous hydrogen bonds, together with its stiff molecular chain, make its dissolution with the most common solvents a difficult process (Cai et al., 2008). The suitable solvent should be capable of breaking the intermolecular hydrogen bonds and minimizing the hydrophobic chain interactions (Yang et al., 2016). Cellulose can be dissolved in alkaline conditions using, for example, cold sodium hydroxide-urea (Cai et al., 2008), or thiourea (Huajin et al., 2007), or in lithium hydroxide(LiOH)-urea-water (Yang et al., 2016), but also in strong acidic media with phosphoric acid-water or sulfuric acidglycerol mixtures (Alves et al., 2016). Novel solvent systems as ionic liquids and deep eutectic solvents have been also proposed for the dissolution of cellulose. Ionic liquids and deep eutectic solvents offer advantages over conventional solvents due to their properties, which can be tuned by adjusting the chemical structure and composition of their constituents (van Osch et al., 2017).

Chitosan and cellulose derivatives, alone or combined, have been widely used to encapsulate different fragrance components, as illustrated through some examples listed in Table 2.
Table 2

Encapsulation of different fragrance components using chitosan and cellulose derivatives alone or combined.

\begin{tabular}{|c|c|c|}
\hline Polymers & $\begin{array}{l}\text { Fragrance } \\
\text { components }\end{array}$ & Reference \\
\hline \multirow[t]{5}{*}{ Chitosan } & Limonene & (Souza et al., 2014) \\
\hline & Citronella & (Hsieh et al., 2006) \\
\hline & Osmanthus & (Hu et al., 2012) \\
\hline & Turmeric & (Lertsutthiwong and \\
\hline & & Rojsitthisak, 2011) \\
\hline \multirow{2}{*}{ Ethylcellulose } & Rosemary & (Voncina et al., 2009) \\
\hline & Lavender & (Wang et al., 2009) \\
\hline Chitosan/Ethylcellulose & Vanillin & (Feczkó et al., 2010) \\
\hline $\begin{array}{l}\text { Chitosan/Sodium } \\
\text { Carboxymethyl Cellulose }\end{array}$ & Neem Seed Oil & (Devi and Kakati, 2011) \\
\hline
\end{tabular}

As far as we know, examples addressing the encapsulation of fragrance components using chitosan and cellulose without modifications to form the encapsulant composite material are scarce. However, the application of sustainable composite materials, as the ones formed by chitosan and cellulose, is very important due to renewability, low cost, biodegradability, and the fact of proceeding from a non-petroleum based source. In addition, the combination of chitosan with cellulose can improve their functional properties thus increasing their applicability in a wider range of fields (H.P.S et al., 2016). Some examples can be cited, as the work carried out by Xiong et al. (2010) that prepared cellulose/chitosan hybrid membranes by regenerating an alkali cellulose solution from a chitosan acidic solution. They reported that the hybrid membranes presented a much denser and homogeneous porous structure after the impregnation of chitosan molecules, thus improving the strength of the hybrid membrane. Other studies attributed antimicrobial potential to cellulose/chitosan blends, as well as high adsorption capacity, high porosity, and metal ions adsorption (Yang et al., 2018). Therefore, it was intended to take advantage of this combination of biopolymers by proposing it as the basis of sustainable composite materials to protect and control the release of fragrances. Recently, Yang et al. (2016) proposed the preparation of cellulose-chitosan composite particles with different sizes and internal structures using $\mathrm{LiOH}$-urea-water and $\mathrm{LiOH}-\mathrm{KOH}-u r e a$ as solvents to dissolve cellulose and chitosan, respectively, via a freezing/thawing/stirring process. Therefore, this work is focused on the application of this methodology, with slight modifications, to dissolve cellulose from a different feedstock, in this case from Eucalyptus globulus, and combine it with chitosan to produce sustainable composite particles to act as delivery vehicles for limonene, which is one of the most applied odorants in the flavor and fragrance industries. For that, cellulose pulp was dissolved using the aqueous solvent composed of $\mathrm{LiOH} /$ urea via a freezing/ thawing/stirring process at $-30^{\circ} \mathrm{C}$ and $-80^{\circ} \mathrm{C}$. The cellulose solution was then dripped into a chitosan solution acidified with acetic acid, to obtain the chitosan-cellulose particles loaded with limonene. The chitosan-cellulose composite particles were characterized in terms of morphology and size by Scanning Electron Microscopy (SEM), Fourier Transform Infrared Spectroscopy (FTIR) and Thermogravimetric

Table 1

Formation of different structures using chitosan, cellulose and cellulose derivatives.

\begin{tabular}{lll}
\hline Polymers & Structures & Reference \\
\hline Chitosan/Carboxymethyl cellulose & Microcapsules & (Zhang et al., 2001) \\
Chitosan/Ethylcellulose & Microspheres & (Martinac et al., 2005) \\
Chitosan/Methylcellulose & Microspheres & (Rokhade et al., 2007) \\
Chitosan/Cellulose & Nanoparticles & (Olivera et al., 2016) \\
& Multicore microparticles & (Remunan-Lopez et al., 1998) \\
& Biocomposites & (H.P.S. et al., 2016) \\
& Spherical nanocomposite particles & (Corsello et al., 2017) \\
& Nanocrystals &
\end{tabular}


Analysis (TGA). Gas chromatography was used to quantify the encapsulated agent (limonene) and to evaluate the release over time.

\section{Materials and methods}

\subsection{Chemicals}

Cellulose (sulfite dissolving pulp), kindly donated by CaimaIndustria de Celulose SA (Constância, Portugal), has the following parameters: $\alpha$-cellulose $(91.9 \pm 0.4 \%)$ and intrinsic viscosity (500 $\pm 50 \mathrm{~cm}^{3} / \mathrm{g}$ ). Chitosan (degree of deacetylation 88-95\%) was purchased from Biolog Biotechnologie Und Logistik (Germany). R(+)-Limonene (purity 97\%) (fragrance) was obtained from Sigma Aldrich and Span 85 (emulsifier) was supplied by Fluka. Lithium hydroxide was supplied by Chem Lab, urea and sodium hydroxide were purchased from José Manuel Gomes dos Santos, LDA (all used to dissolve cellulose) and acetic acid (used to dissolve chitosan) was provided by Sigma Aldrich. $t$-Butanol (99.5\%) (washing reagent) was supplied by Merck.

\subsection{Dissolution of cellulose and chitosan biopolymers}

Cellulose pulp dissolution was achieved using different aqueous solvents following the procedure described by Yang et al. (2016) with slight modifications. First, a solvent composed of LiOH-urea-water (4.6:15:80.4) wt $\%$ was prepared and frozen. Then, $1 \mathrm{~g}$ of cellulose pulp (previously crushed) was added to $99 \mathrm{~g}$ of LiOH-urea-water thawed solvent for $5 \mathrm{~min}$ at $1300 \mathrm{rpm}$. The mixture was kept at $-30{ }^{\circ} \mathrm{C}$ until it was completely frozen and then thawed at room temperature and further stirred at $1300 \mathrm{rpm}$ for $3 \mathrm{~min}$. The procedure was also carried out with a freezing temperature of $-80^{\circ} \mathrm{C}$. This freezing/thawing/stirring cycle was repeated four times more for both temperatures $\left(-30^{\circ} \mathrm{C}\right.$ and $-80^{\circ} \mathrm{C}$ ) until a transparent cellulose solution was obtained.

For the preparation of $1 \%(\mathrm{w} / \mathrm{w})$ chitosan solution, chitosan was dissolved in of $1 \mathrm{M}$ acetic acid and left under magnetic stirring for $15 \mathrm{~h}$ to ensure complete dissolution.

\subsection{Preparation of empty chitosan-cellulose composite particles}

For the preparation of chitosan-cellulose composite particles, $5 \mathrm{~mL}$ of the previously prepared $1 \%(\mathrm{w} / \mathrm{w})$ cellulose solution were added dropwise to the $1 \%(\mathrm{w} / \mathrm{w})$ chitosan solution $(100 \mathrm{~mL})$, at a constant stirring speed of $200 \mathrm{rpm}$. After the formation/maturation of chitosancellulose particles, the solution was filtered using a Buchner funnel and a filter paper with pore size of $12-15 \mu \mathrm{m}$. Thereafter, particles were extensively washed with deionized water followed by solvent exchange from water to $t$-butanol. The obtained chitosan-cellulose particles were collected onto a petri dish, which was placed in the freezer at $-24^{\circ} \mathrm{C}$ overnight.

\subsection{Encapsulation of limonene in chitosan-cellulose composite particles}

For the encapsulation of limonene, a solution composed of $2 \mathrm{~g}$ of the fragrant component and $0.18 \mathrm{~g}$ of Span 85 (HLB of 1.8), an emulsifier often used in cosmetic and textile industries (Martins et al., 2011), was prepared. This mixture was added to $100 \mathrm{~g}$ of chitosan solution with stirring at $500 \mathrm{rpm}$. The solution was then mixed in the homogenizer for $2 \mathrm{~min}$ and a homogeneous white solution was obtained. Then, $5 \mathrm{~mL}$ of the $1 \%(\mathrm{w} / \mathrm{w})$ cellulose solution were added to the chitosan solution under manual shaking. Particles were filtered with a filter with thickness equal to $0.20 \mathrm{~mm}$ and pore size of $12-15 \mu \mathrm{m}$, and extensively washed with deionized water, followed by solvent exchange from water to t-butanol before freezing.

\subsection{Chemical and physical characterization}

The dissolution of cellulose pulp was confirmed by optical microscopy using a Leica DM 2000 apparatus equipped with a Leica Application Suite Interactive Measurement imaging software.

The morphology of particles and their size were evaluated macroscopically and by a high-resolution (Schottky) Environmental Scanning Electron Microscope with X-Ray Microanalysis and Electron Backscattered Diffraction Analysis: Quanta 400 FEG ESEM/EDAX Genesis $\mathrm{X} 4 \mathrm{M}$ operating at $15.00 \mathrm{kV}$. For this characterization, the particles were freeze-dried and, then coated with gold/palladium thin film by sputtering using the SPI Module Sputter Coater.

In order to access molecular interactions between chitosan and cellulose, Fourier Transform Infrared Spectroscopy (FTIR) was used. The spectra were obtained on ABB Inc. equipment, model MB3000 (Quebec, Canada) operating in Attenuated Total Reflectance (ATR) mode, using a Miracle single reflection horizontal ATR accessory from Pike Technologies (Madison, WI, USA). Spectra were recorded between 550 and $4000 \mathrm{~cm}^{-1}$ at a resolution of $16 \mathrm{~cm}^{-1}$ and cumulative 32 scans. Spectra were acquired using the software Horizon MB v.3.4. No baseline correction was performed. All the materials were dried before analysis. Thermogravimetric analysis (TGA) was also performed using a TG model 209F3 Tarsus (Selb, Germany). For each sample, $5.5 \mathrm{mg}$ were weighted into alumina crucibles. The analyses were made by heating the sample from 30 until $700{ }^{\circ} \mathrm{C}$ at a constant heating rate of $10{ }^{\circ} \mathrm{C} / \mathrm{min}$ under nitrogen flow $(20 \mathrm{ml} / \mathrm{min})$. Thermograms were treated with Netzsch Proteus thermal analysis software, version 5.2.1. The samples were dried before analysis.

The quantification of the fragrant molecule limonene was assessed using a Varian CP-3800 gas chromatographer equipped with a split/ splitless injector, Rxi- 5Sil MS column ( $30 \mathrm{~m}$ x0.25 mm with $0.25 \mu \mathrm{m}$ film thickness) and a flame ionization detector (FID). The oven temperature program was initially set at $80^{\circ} \mathrm{C}$ then raised to $150{ }^{\circ} \mathrm{C}$ at a heating rate of $4{ }^{\circ} \mathrm{C} / \mathrm{min}$. The flow rate of the carrier gas (Helium N60) was $1.2 \mathrm{~mL} / \mathrm{min}$ and the injector and detector temperatures were set at $240{ }^{\circ} \mathrm{C}$ and $250^{\circ} \mathrm{C}$, respectively.

To determine the encapsulation efficiency, $2 \mathrm{~mL}$ from the whole filtrate solution were filtered through $0.4 \mu \mathrm{m}$ pore size polypropylene filter, and a volume of $0.1 \mu \mathrm{L}$ was injected in the GC-FID with a split ratio of 20:1. Quantification was based on the respective calibration curve previously determined under the same experimental conditions. The encapsulation efficiency $(E E \%)$ was calculated according to the following equation:

$\mathrm{EE}(\%)=\frac{\text { mass }_{\text {total }}(\mathrm{g})-\text { mass }_{\text {non-encapsulated }}(\mathrm{g})}{\text { mass }_{\text {total }}(\mathrm{g})} \times 100$

where mass total $_{\text {is }}$ the mass of limonene used in the formulation to prepare the microparticles, in $g$, and mass non-encapsulated $_{\text {is }}$ the mass of the non-encapsulated limonene, in $g$.

The limonene release was evaluated through headspace analysis for $162 \mathrm{~h}$. For that, particles were placed in a $20 \mathrm{~mL}$ closed-cap headspace vial at a controlled room temperature $\left(23 \pm 1{ }^{\circ} \mathrm{C}\right)$. Then, a gas sampling volume $(0.4 \mathrm{~mL})$ was injected in the GC-FID and the concentration of limonene $\left(\mathrm{C}_{\text {limonene }}^{\text {gas }}\right)$ estimated according to Eq. 2.

$\mathrm{C}_{\text {limonene }}^{\text {gas }}(\mathrm{g} / \mathrm{mL})=\frac{\text { mass of limonene }}{\mathrm{V}_{\text {limonene }}^{\text {gas }}}(1+$ split $)$

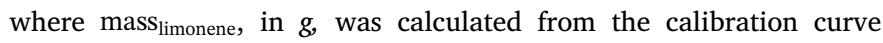
evaluated under the same experimental conditions, and volume corresponds to the injected volume (mL). Considering a volume of solution equal to the volume of the vial $(20 \mathrm{~mL})$, volume ${ }_{\text {vial }}$, it was possible to calculate the released mass of limonene (Eq. 3). The released limonene (Released (\%)) was calculated from the quotient between the amount of released mass of limonene (mass released $_{\text {) }}$ (Eq. 3) and the initial mass of limonene present in the loaded chitosan-cellulose composite 


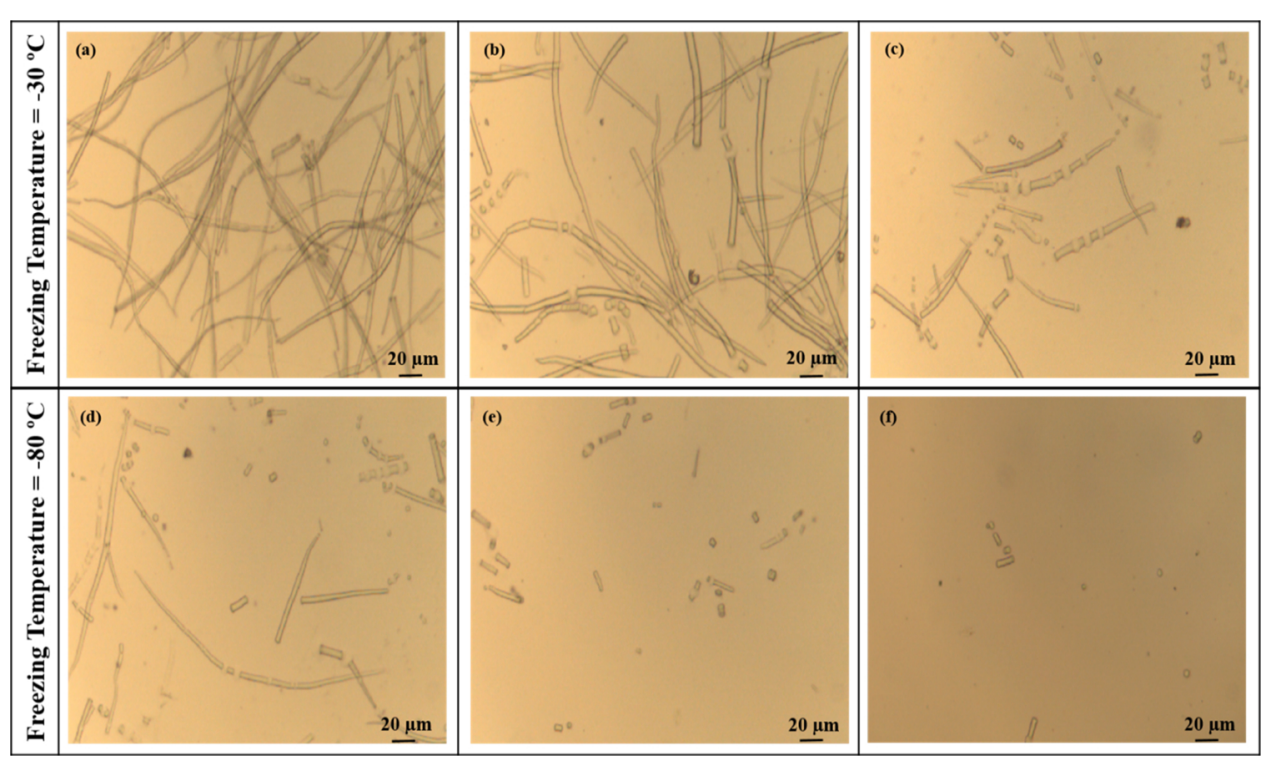

Fig. 1. Optical microscopy images (20 $\square)$ of cellulose pulp after: (a) one freezing/thawing/ stirring cycle, (c) four freezing/thawing/stirring cycles, at a freezing temperature of $-30{ }^{\circ} \mathrm{C}$ and (d) one freezing/thawing/stirring cycle, (e) two freezing/thawing/stirring cycles and (f) four freezing/thawing/stirring cycles, at a freezing temperature of $-80^{\circ} \mathrm{C}$. particles (mass initial $_{\text {) }}$, (both expressed in $\mathrm{g}$ ) as shown in Eq. 4.

$\operatorname{mass}_{\text {released }}(\mathrm{g})=\mathrm{C}_{\text {limonene }}^{\text {gas }}(\mathrm{g} / \mathrm{mL}) \times$ volume $_{\text {vial }}(\mathrm{mL})$

Released $(\%)=\frac{\text { mass }_{\text {released }}(\mathrm{g})}{\text { mass }_{\text {initial }}(\mathrm{g})} \times 100$

\section{Results and discussion}

\subsection{Dissolution of cellulose}

The optical microscopy images acquired for cellulose pulp after one, two and four freezing/thawing/stirring cycles at a freezing temperature of $-30^{\circ} \mathrm{C}$ are displayed in Fig. 1(a), (b) and (c), respectively. Fig. 1 also shows the cellulose aspect after one (d), two (e) and four (f) freezing/ thawing/stirring cycles at a freezing temperature of $-80^{\circ} \mathrm{C}$.

Results showed that, unlike to the ones described by Yang et al. (2016), where two freezing/thawing/stirring cycles at a freezing temperature of $-30{ }^{\circ} \mathrm{C}$ were enough to dissolve cellulose pulp, in the present study, four freezing/thawing/stirring cycles were required. Inspecting Fig. 1, it was found that the cellulose fibers were more effectively dissolved at a freezing temperature of $-80^{\circ} \mathrm{C}$, that is, the large size fibbers were scarce and around $20 \mu \mathrm{m}$ size. The effect of temperature on cellulose dissolution has been reported by other authors (Cai et al., 2008; Qi et al., 2008; Cai and Zhang, 2005). In addition, it seems that cellulose dissolution results from a self-assembly process among solvent small molecules and the cellulose macromolecules. Qi et al. (2008) tested the dissolution of cellulose with different viscosity-average molecular weight using $7 \mathrm{wt} \% \mathrm{NaOH}-12 \mathrm{wt} \%$ urea aqueous solution at temperatures from $-12{ }^{\circ} \mathrm{C}$ to $60^{\circ} \mathrm{C}$. Authors concluded that when solid cellulose was submerged in $\mathrm{NaOH} /$ urea aqueous solution at $-12.6^{\circ} \mathrm{C}$, the hydrogen-bonded network structure between the cellulose macromolecules and the solvent small molecules was created rapidly to form an inclusion complex, transporting cellulose into the aqueous solution. The findings reported by Qi et al. (2008) are in agreement with the ones performed by Cai et al. (2008), since they reported that cellulose dissolution at $-12{ }^{\circ} \mathrm{C}$ results from a fast dynamic self-assembly process among solvent small molecules and the cellulose macromolecules. In 2005, the same authors had already concluded that the alkali hydrates, urea hydrates and free water can penetrate cellulose structure and destroy the intra and inter molecular hydrogen bonding at low temperature, causing solvation of the cellulose chains, when studying the dissolution behaviour and solubility of cellulose in $\mathrm{LiOH}$-urea and $\mathrm{NaOH}-$ urea aqueous solutions pre-cooled to $-10^{\circ} \mathrm{C}$ (Cai and Zhang, 2005). Cai et al. (2008) suggest that the cellulose dissolution process by cooling may be related to the formation of hydrogen-bonded networks between cellulose and solvent molecules. In addition, other authors have proved that the dissolution process of several celluloses is dependent on their degree of polymerization, crystallinity index, and the corresponding supramolecular structure (Isogai and Atalla, 1998; Ramos et al., 2005; Cai et al., 2008). Therefore, celluloses with distinct characteristics, and the use of different solvent systems, lead to different experimental conditions for cellulose dissolution.

\subsection{Morphology of chitosan-cellulose composite particles}

The experimental procedure described in the present study allowed the production of particles with oval and spherical shapes and with an average diameter of $2 \mathrm{~mm}$ (hydrated form) (Fig. 2). The morphology of the empty and limonene-loaded chitosan-cellulose composite particles

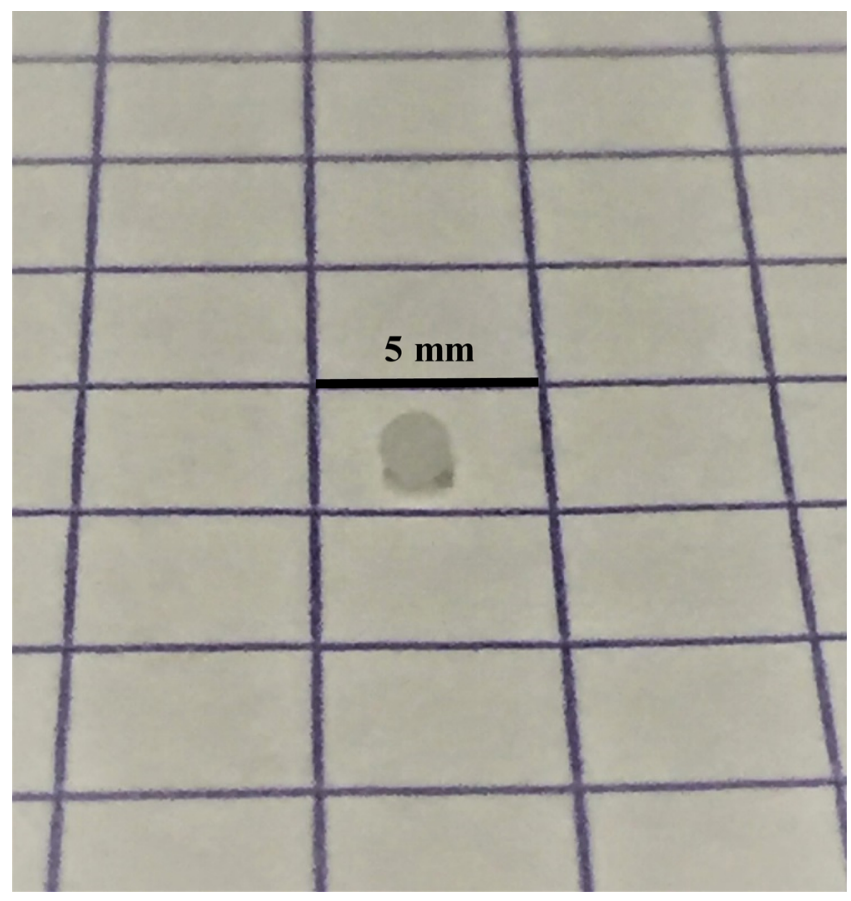

Fig. 2. Macroscopic image of a chitosan-cellulose composite particle. 


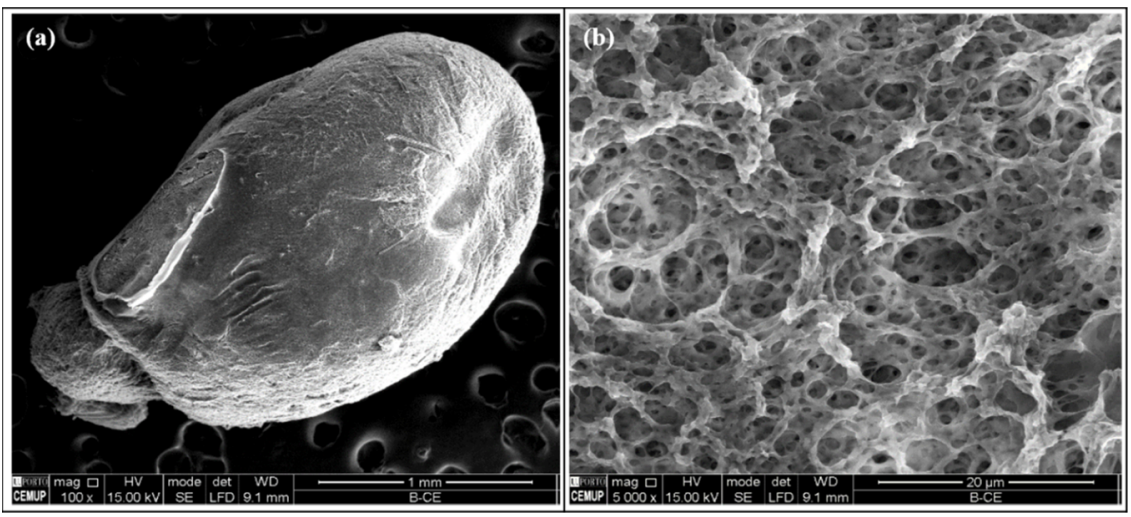

Fig. 3. SEM images of empty chitosan-cellulose composite particles.

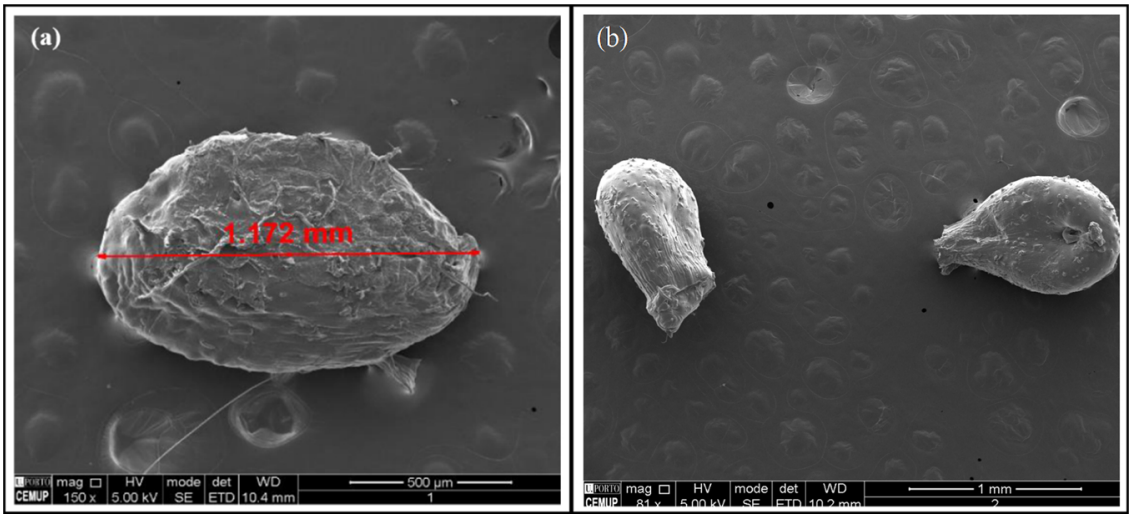

Fig. 4. SEM images of limonene-loaded chitosan-cellulose composite particles.

was also analysed using a high-resolution environmental Scanning Electron Microscope (SEM). As it can be seen in Fig. 3(a) empty chitosan-cellulose particles present an oval shape, probably due to the freeze-drying step required for the SEM analysis. Chitosan-cellulose particles presented sizes between 1 and $2 \mathrm{~mm}$ and a surface morphology characterized by a fine porous network structure (Fig. 3(b)). Regarding the chitosan-cellulose particles containing limonene (Fig. 4), it was observed that the particles exhibit a similar size and shape, but with some particles resembling the spherical shape (Fig. 4(b)).

\subsection{Molecular interactions in chitosan-cellulose composite particles}

Dropping cellulose into the acidic chitosan solution causes polymer's mixing at the interface of the cellulose droplet. It is on the outermost surface of the cellulose droplets that the co-regeneration starts, and where entanglements between cellulose and chitosan chains are developed during the solidification phase, slowing down chitosan diffusion from the microparticle's surface to the core. This explain why the surface of these composites are rich in chitosan (Yang et al., 2016). To corroborate these results, Xiong et al. (2010), who developed a method to prepare an adsorptive membrane by impregnating chitosan into a regenerated cellulose membrane, found that chitosan chains are distributed at membrane's surface.

FTIR analysis was used in our work to evaluate the molecular interactions occurring between cellulose and chitosan, which can evidence the level of affinity between the two polymers. Fig. 5 shows the FTIR spectra of both biopolymers (chitosan and cellulose), and the empty and limonene-loaded chitosan-cellulose composite particles. Regarding the cellulose spectrum (Fig. 5(a)), the vibration identified at $3340 \mathrm{~cm}^{-1}$ is attributed to the $\mathrm{OH}$ stretching vibration, while the peaks at 2915 and $1426 \mathrm{~cm}^{-1}$ are related with the $\mathrm{CH}$ stretching and bending of the $\mathrm{CH}_{2}$ groups, respectively. Analysing the chitosan spectrum (Fig. 5(b)), the broad band detected between 3400 and $3200 \mathrm{~cm}^{-1}$ is attributed to the $\mathrm{OH}$ and $\mathrm{NH}$ stretching, while the most characteristic absorption bands are assigned at 1648 and $1574 \mathrm{~cm}^{-1}$, corresponding to the $\mathrm{C}=\mathrm{O}$ stretching and the $\mathrm{NH}$ bending of amide I and amide II, respectively. For the empty chitosan-cellulose composite particles (Fig. 5(c)), evidences of the interaction between the two polymers (development of hydrogen bonds) were identified based on the shifting of the chitosan $\mathrm{C}=\mathrm{O}$ vibration from 1648 to 1661 and $\mathrm{cm}^{-1}$, the intensity decrease of the $\mathrm{NH}$ peak at $1574 \mathrm{~cm}^{-1}$, and the appearing of a vibration at $3440 \mathrm{~cm}^{-1}$ in the $\mathrm{OH}$ region. This corroborates the good affinity between the two biopolymers and the formation of more cohesive materials. These features are also observed in the limoneneloaded chitosan-cellulose particles proving that the active principle does not hinder the development of molecular interactions between the two polymers (Fig. 5(d)).

For TGA analysis, the pure components (cellulose and chitosan), the empty and limonene-loaded chitosan-cellulose composite particles, were considered. The degradation patterns and the DTG curves are shown in Figs. 6 and 7. Analysing the thermal degradation of cellulose (Fig. 6(a) and 7(a)), a sole degradation stage comprised between 256 and $406^{\circ} \mathrm{C}$ is identified, with a maximum degradation temperature of $361^{\circ} \mathrm{C}$. For chitosan (Fig. 6(b) and 7(b)), a two-stage degradation 


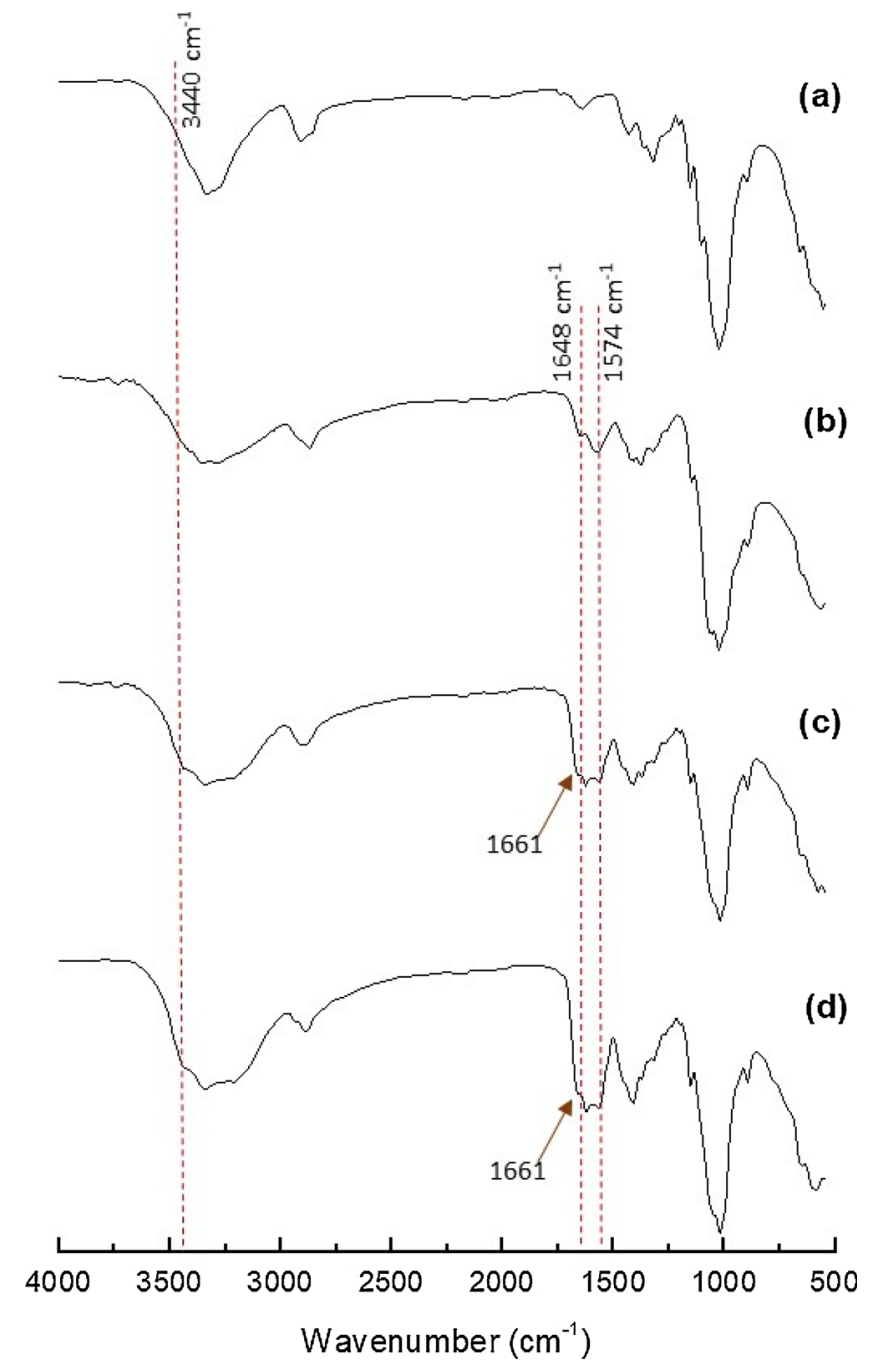

Fig. 5. FTIR spectra of (a) chitosan, (b) cellulose, (c) empty chitosan-cellulose composite particles, and (d) limonene-loaded chitosan-cellulose composite particles.

pattern is noticed, namely a first stage $\left(30\right.$ and $\left.116^{\circ} \mathrm{C}\right)$ ascribed to water removal, and a second one $\left(221-403^{\circ} \mathrm{C}\right.$; maximum degradation temperature of $297^{\circ} \mathrm{C}$ ) related with the degradation of chitosan backbone, namely the scission of the glycosidic bonds between the glucosamine and $\mathrm{N}$-acetylglucosamine moieties. The final obtained final residue was $39.04 \%$. Regarding the empty chitosan-cellulose composite particles (Fig. 6(c) and 7(c)), two degradation stages were assigned, the first one correspond to the water and acetic acid removal (until $200^{\circ} \mathrm{C}$ ), and the third one to the chitosan-cellulose composite degradation $\left(200{ }^{\circ} \mathrm{C}-405^{\circ} \mathrm{C}\right.$; maximum degradation temperature of $\left.313^{\circ} \mathrm{C}\right)$. The obtained final residue, which corresponds to the sample mass without being degraded, was $31.04 \%$. This behaviour is compatible with the mixture of the two individual components, cellulose and chitosan. Looking at the limonene-loaded chitosan-cellulose composite particles, a similar degradation pattern to the empty particles was observed. However, the final residue was lower (27\%, comparatively with $31.04 \%$ ), as well as the maximum degradation temperature $\left(292^{\circ} \mathrm{C}\right.$, comparatively with $313^{\circ} \mathrm{C}$ ). This can be related with the presence of limonene, which might weaken the molecular interactions between

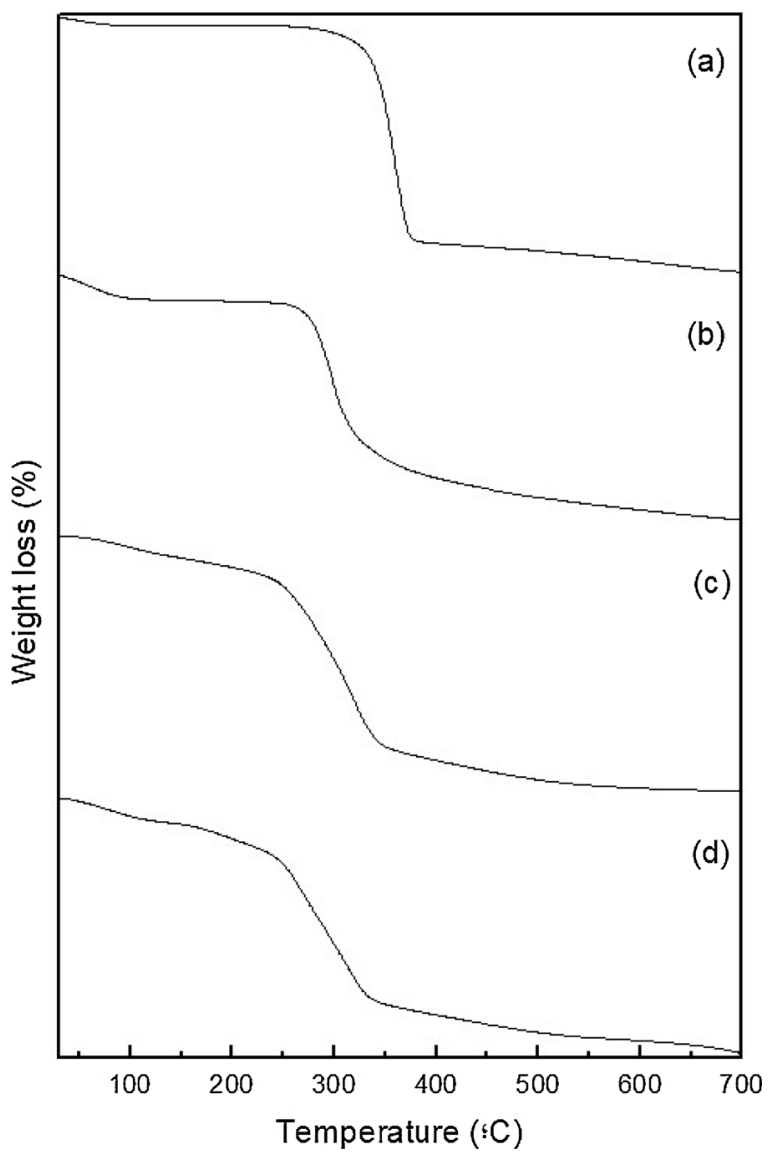

Fig. 6. TGA results: weight loss of (a) cellulose, (b) chitosan, (c) empty chitosan-cellulose composite particles, and (d) limonene-loaded chitosan-cellulose composite particles.

cellulose and chitosan, leading to a slightly less cohesive material.

\subsection{Encapsulation efficiency and release of limonene}

The proposed methodology allowed an acceptable encapsulation efficiency of $51.29 \%$. The use of Span 85 as emulsifier could origin low distribution of the oil within the composite particles, leading to this encapsulation efficiency. Therefore, as future work, we suggest investigating the effect of different emulsifier agents on the encapsulation efficiency of limonene-loaded chitosan-cellulose composite particles.

In respect to the release profile of limonene over time (Fig. 8), two phases were observed: an initial phase (first $24 \mathrm{~h}$ ) characterized by a burst release effect, probably due to the release of limonene found on the outermost surface of particles, followed by a decrease release over $162 \mathrm{~h}$. It is important to note that the release studies were performed in order to have some first insights concerning the release pattern of limonene from the developed particles. Therefore, the adequacy of the presented level of release for a certain application demands further studies, including a well-established target level. Moreover, this aspect could be also modulated by producing microparticles with higher limonene loads (higher limonene amounts in the formulation can be used). According to our qualitative analysis (data not showed), although at lower concentrations, limonene aroma was still perceptible after the analysis period. 


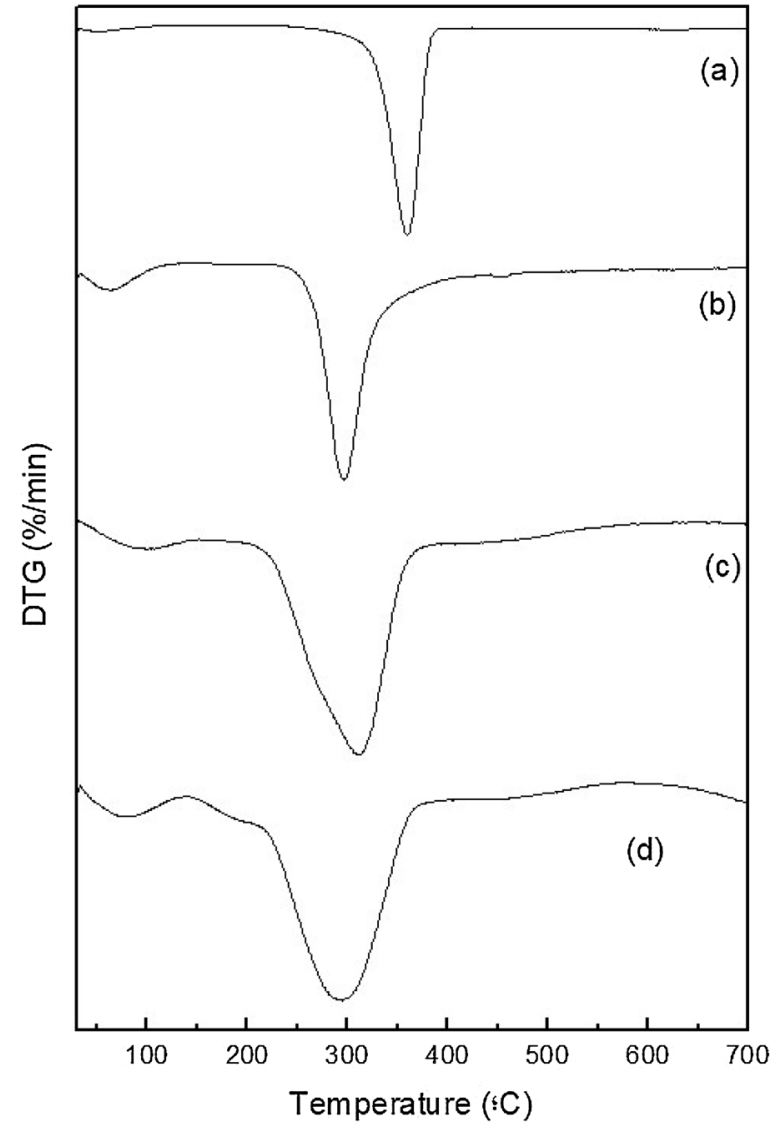

Fig. 7. DTG curves (a) cellulose, (b) chitosan, (c) empty chitosan-cellulose composite particles, and (d) limonene-loaded chitosan-cellulose composite particles.

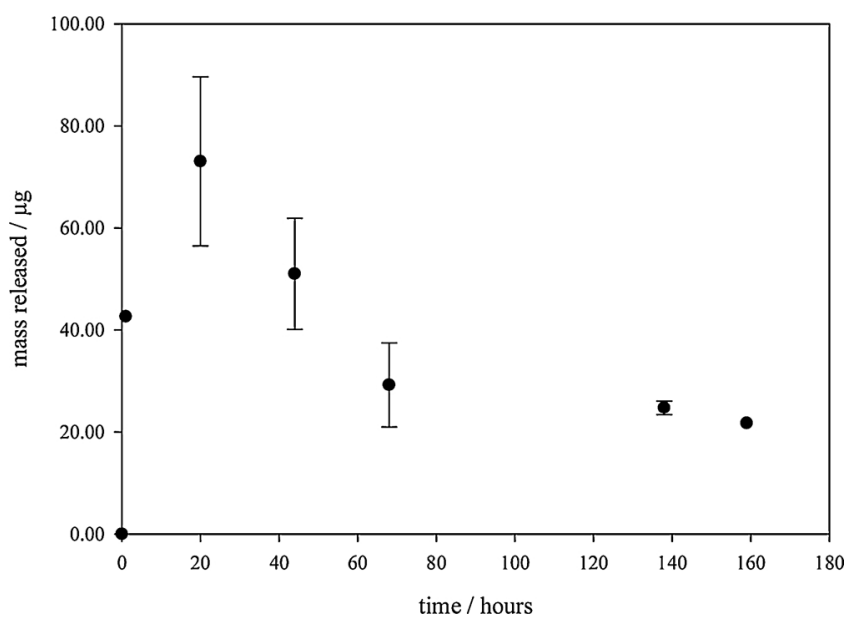

Fig. 8. Release profile of limonene for $162 \mathrm{~h}$.

\section{Conclusions}

In the present study, chitosan-cellulose particles aiming at encapsulating limonene were produced. The dissolution of the cellulose pulp was attained using an aqueous solvent composed of LiOH/urea, and different freezing/thawing/stirring cycles at two freezing temperatures, -30 and $-80^{\circ} \mathrm{C}$. Results showed that a freezing temperature of $-80^{\circ} \mathrm{C}$, together with four freezing/thawing/stirring cycles, resulted in the optimal conditions to efficiently dissolve the cellulose pulp. After that, chitosan-cellulose particles with spherical to oval shapes were formed with dimensions comprised between 1 and $2 \mathrm{~mm}$. SEM photographs also confirmed the oval and spherical morphology of these particles and its size (1-2 mm). The encapsulation of $2 \mathrm{~g}$ of limonene (core material) in the chitosan-cellulose particles was thereafter carried out. These particles displayed also dimensions between 1 and $2 \mathrm{~mm}$ and a similar shape comparatively to empty cellulose-chitosan composite particles. The results from FTIR and TGA analyses allowed concluding that a good compatibility between cellulose and chitosan was achieved, and that the presence of limonene has a slightly effect on the cohesiveness of the final obtained material. An acceptable encapsulation efficiency was reached $(51.29 \%)$. The release of limonene from the chitosan-cellulose particles was more pronounced during the first $24 \mathrm{~h}$, followed by a decrease release until a time-frame of $162 \mathrm{~h}$. Therefore, these results corroborate that LiOH-urea-water together with freezing/ thawing/stirring process is an efficient approach to promote cellulose dissolution. In addition, the reported findings suggest that chitosancellulose composite particles are valid systems to encapsulate fragrances.

\section{Acknowledgments}

This work was financially supported by: Associate Laboratory LSRELCM - UID/EQU/50020/2019 - funded by national funds through FCT/ MCTES (PIDDAC). This work is a result of: Project "AIProcMat@N2020 - Advanced Industrial Processes and Materials for a Sustainable Northern Region of Portugal 2020", with the reference NORTE-010145-FEDER-000006, supported by Norte Portugal Regional Operational Programme (NORTE 2020), under the Portugal 2020 Partnership Agreement, through the European Regional Development Fund (ERDF); Associate Laboratory LSRE-LCM - UID/EQU/50020/2019 - funded by national funds through FCT/MCTES (PIDDAC). CIMO (UID/ AGR/00690/2019) through FEDER under Program PT2020. P. Costa acknowledges her postdoctoral grant from FCT (SFRH/BPD/93108/ 2013). To the national funding by FCT, P.I., through the institutional scientific employment program-contract for I.P. Fernandes contract.

\section{References}

Alonso, D., Gimeno, M., Olayo, R., Vázquez-Torres, H., Sepúlveda-Sánchez, J., Shirai, K., 2009. Cross-linking chitosan into UV-irradiated cellulose fibers for the preparation of antimicrobial-finished textiles. Carbohydr. Polym. 77, 536-543. https://doi.org/10. 1016/j.carbpol.2009.01.027.

Alves, L., 2015. Cellulose Solutions: Dissolution, Regeneration, Solution Structure and Molecular Interactions. PhD Thesis. http://hdl.handle.net/10316/2931.

Alves, L., Medronho, B., Antunes, F., Topgaard, D., Lindman, B., 2016. Dissolution state of cellulose in aqueous systems. 2. Acidic solvents. Carbohydr. Polym. 151, 707-715. https://doi.org/10.1016/j.carbpol.2016.06.015.

Bauer, K., Garbe, D., Surburg, H., 2006. Common Fragrance and Flavor Materials: Preparation, Properties and Uses, fifth ed. Wiley-VCH, Weinheim.

Cai, J., Zhang, L., 2005. Rapid dissolution of cellulose in $\mathrm{LiOH} / \mathrm{urea}$ and $\mathrm{NaOH} / \mathrm{urea}$ aqueous solutions. Macromol. Biosci. 5, 539-548. https://doi.org/10.1002/mabi. 200400222.

Cai, J., Zhang, L., Liu, S., Liu, Y., Xu, X., Chen, X., Chu, B., Guo, X., Xu, J., Cheng, H., 2008. Dynamic self-assembly induced rapid dissolution of cellulose at low temperatures. Macromolecules 41, 9345-9351. https://doi.org/10.1021/ma801110g.

Carvalho, I.T., Estevinho, B.N., Santos, L., 2015. Application of microencapsulated essential oils in cosmetic and personal healthcare products-a review. Int. J. Cosmet. Sci. Title 38, 108-119. https://doi.org/10.1111/ics.12232.

Corsello, F.A., Bolla, P.A., Anbinder, P.S., Serradell, M.A., Amalvy, J.I., Peruzzo, P.J., 2017. Morphology and properties of neutralized chitosan-cellulose nanocrystals biocomposite films. Carbohydr. Polym. 156, 452-459. https://doi.org/10.1016/j. carbpol.2016.09.031.

Devi, N., Kakati, D.K., 2011. Study of complex coacervation of chitosan with sodium carboxymethyl cellulose: microencapsulation of neem seed oil and isoniazid. Int. J. Phys. Sci. 60, 1091-1105. https://doi.org/10.1080/00914037.2011.553851.

Duarte, H.M.M., 2014. Desenvolvimento E Caracterização De Solventes Aquosos Para a Dissolução De Celulose: Reologia E Comportamento De Fase. Master Thesis. https:// core.ac.uk/download/pdf/61523255.pdf.

Estevinho, B.N., Rocha, F., Santos, L., Alves, A., 2013. Microencapsulation with chitosan by spray drying for industry applications-A review. Trends Food Sci. Technol. 31, 
138-155. https://doi.org/10.1016/j.tifs.2013.04.001.

Feczkó, T., Kokol, V., Voncina, B., 2010. Preparation and characterization of ethylcellulose-based microcapsules for sustaining release of a model fragrance. Macromol Re. 18, 636-640. https://doi.org/10.1007/s13233-010-0701-z.

Fortineau, A., 2004. Chemistry perfumes your daily life. J. Chem. Educ. 81, 45. https:// doi.org/10.1002/3527608214.

Hosseinkhani, B., Callewaert, C., Vanbeveren, N., Boon, N., 2015. Novel biocompatible nanocapsules for slow release of fragrances on the human skin. New Bioeth. 32, 40-46. https://doi.org/10.1016/j.nbt.2014.09.001.

Abdul Khalil, H.P.S., Saurabh, C.K., Adnan, A.S., Fazita, M.R.N., Syakir, M.I., Davoudpour, Y., Rafatullah, M., Abdullah, C.K., Haafiz, M.K.M., Dungani, R., 2016. A review on chitosan-cellulose blends and nanocellulose reinforced chitosan biocomposites: properties and their applications. Carbohydr. Polym. 150, 216-226. https://doi.org/10.1016/j.carbpol.2016.05.028.

Hsieh, W., Chang, C., Gao, Y., 2006. Controlled release properties of chitosan encapsulated volatile citronella oil microcapsules by thermal treatments. Colloids Surf. B Biointerfaces 53, 209-214. https://doi.org/10.1016/j.colsurfb.2006.09.008.

Hu, J., Xiao, Zb., Ma, Ss., Zhou, Rj., Wang, Mx., Li, Z., 2012. Properties of osmanthus fragrance-loaded chitosan-sodium tripolyphosphate nanoparticles delivered through cotton fabrics. J. Appl. Polym. Sci. 123, 3748-3754. https://doi.org/10.1002/app. 34733.

Huajin, J., Zha, C., Gu, L., 2007. Direct dissolution of cellulose in $\mathrm{NaOH} /$ thiourea/urea aqueous solution. Carbohydr. Res. 342, 851-858. https://doi.org/10.1016/j.carres. 2006.12.023.

Isogai, A., Atalla, R.H., 1998. Dissolution of cellulose in aqueous $\mathrm{NaOH}$ solutions. Cellulose 5, 309-319. https://doi.org/10.1023/A:1009272632367.

Lertsutthiwong, P., Rojsitthisak, P., 2011. Chitosan-alginate nanocapsules for encapsulation of turmeric oil. Pharmazie 66, 911-915. https://doi.org/10.1691/ph. 2011.1068.

Liao, Z., Xue, D., Li, H., Shi, L., 2016. Fragrance-containing microcapsules based on interfacial thiol-Ene polymerization. J. Appl. Polym. Sci. 136. https://doi.org/10.1002/ app. 43905 .

Lindman, B., Karlström, G., Stigsson, L., 2010. On the mechanism of dissolution of cellulose. J. Mol. Liq. 156, 76-81. https://doi.org/10.1016/j.molliq.2010.04.016.

Martinac, A., Filipović-Grčić, J., Voinovich, D., Perissutti, B., Franceschinis, E., 2005 Development and bioadhesive properties of chitosan-ethylcellulose microspheres for nasal delivery. Int. J. Pharm. 291, 69-77. https://doi.org/10.1016/j.ijpharm.2004. 07.044.

Martins, I.M., Rodrigues, S.N., Barreiro, M.F., Rodrigues, A.E., 2011. Polylactide-based thyme oil microcapsules production: evaluation of surfactants. Ind. Eng. Chem. Res. 50, 898-904. https://doi.org/10.1021/ie101815f.

Martins, I.M., Barreiro, M.F., Coelho, M., Rodrigues, A.E., 2014. Microencapsulation of essential oils with biodegradable polymeric carriers for cosmetic applications. Chem. Eng. J. 245, 191-200. https://doi.org/10.1016/j.cej.2014.02.024.

Oliveira, F.S., 2015. Microencapsulação de extratos naturais ricos em flavonoides visando o desenvolvimento de alimentos funcionais com propriedades quimiopreventivas. Master thesis. https://bibliotecadigital.ipb.pt/handle/10198/12400.

Olivera, S., Muralidhara, H.B., Venkatesh, K., Guna, V.K., Gopalakrishna, K., Kumar, Y., 2016. Potential applications of cellulose and chitosan nanoparticles/composites in wastewater treatment: a review. Carbohydr. Polym. 153, 600-618. https://doi.org/ 10.1016/j.carbpol.2016.08.017.
Peña, B., Casals, M., Torras, C., Gumí, T., Garcia-Valls, R., 2008. Vanillin release from polysulfone macrocapsules. Ind. Eng. Chem. Res. 48, 1562-1565. https://doi.org/10. 1021/ie801133f.

Pena, B., Panisello, C., Aresté, G., Garcia-Valls, R., Gumí, T., 2012. Preparation and characterization of polysulfone microcapsules for perfume release. Chem. Eng. J. 179, 394-403. https://doi.org/10.1016/j.cej.2011.10.090.

Qi, H., Chang, C., Zhang, L., 2008. Effects of temperature and molecular weight on dissolution of cellulose in $\mathrm{NaOH} /$ urea aqueous solution. Cellulose 15, 779-787. https:// doi.org/10.1007/s10570-008-9230-8.

Ramos, L.A., Assaf, J.M., El Seoud, O.A., Frollini, E., 2005. Influence of the supramolecular structure and physicochemical properties of cellulose on its dissolution in a lithium chloride/N,N-dimethylacetamide solvent system. Biomacromolecules. 6 , 2638-2647. https://doi.org/10.1021/bm0400776.

Remunan-Lopez, C., Lorenzo-Lamosa, M.L., Vila-Jato, J.L., Alonso, M.J., 1998. Development of new chitosan-cellulose multicore microparticles for controlled drug delivery. Eur. J. Pharm. Biopharm. 45, 49-56. https://doi.org/10.1016/S09396411(97)00122-7.

Rokhade, A.P., Shelke, N.B., Patil, S.A., Aminabhavi, T.M., 2007. Novel interpenetrating polymer network microspheres of chitosan and methylcellulose for controlled release of theophylline. Carbohydr. Polym. 69, 678-687. https://doi.org/10.1016/j.carbpol. 2007.02.008.

Souza, J.M., Caldas, A.L., Tohidi, S.D., Molina, J., Souto, A.P., Fangueiro, R., Zille, A., 2014. Properties and controlled release of chitosan microencapsulated limonene oil. Rev. Bras. Farmacogn. 24, 691-698. https://doi.org/10.1016/j.bjp.2014.11.007.

Tekin, R., Bac, N., Erdogmus, H., 2013. Microencapsulation of fragrance and natural volatile oils for application in cosmetics, and household cleaning products. Macromol. Symp. 333, 35-40. https://doi.org/10.1002/masy.201300047.

van Osch, D.J.G.P., Kollau, L.J.B.M., van den Bruinhorst, A., Asikainen, S., Rocha, M.A.A., Kroon, M.C., 2017. Ionic liquids and deep eutectic solvents for lignocellulosic biomass fractionation. Phys. Chem. Chem. Phys. 19, 2636-2665. https://doi.org/10. 1039/C6CP07499E.

Voncina, B., Kreft, O., Kokol, V., Chen, W.T., 2009. Encapsulation of rosemary oil in ethylcellulose microcapsules. Textile Polym. J. 1 (13), 13-19.

Wang, Jin-Mei, Zheng, W., Song, Q., Zhu, H., Zhou, Y., 2009. Preparation and characterization of natural fragrant microcapsules. J. Fiber Bioeng. Info. 1, 293-300. https://doi.org/10.3993/jfbi03200907.

Xiao, Z., Liu, W., Zhu, G., Zhou, R., Niu, Y., 2014. A review of the preparation and application of flavour and essential oils microcapsules based on complex coacervation technology. J. Sci. Food Agric. 94, 1482-1494. https://doi.org/10.1002/jsfa.6491.

Yang, J., Kwon, G.-J., Hwang, K., Kim, D.-Y., 2018. Cellulose-chitosan antibacterial composite films prepared from LiBr solution. Polymers. 10, 1-10. https://doi.org/10. 3390/polym10101058.

Yang, J., Duan, J., Zhang, L., Lindman, B., Edlund, H., Norgren, M., 2016. Spherical nanocomposite particles prepared from mixed cellulose-chitosan solutions. Cellulose. 23, 3105-3115. https://doi.org/10.1007/s10570-016-1029-4.

Zhang, L., Jin, Y., Liu, H., Du, Y., 2001. Structure and control release of chitosan/carboxymethyl cellulose microcapsules. J. Appl. Polym. Sci. 82, 584-592. https://doi. org/10.1002/app.1886.

Zhu Yong, G., Xiao, Z.B., Zhou, R.J., Yi, F.P., 2012. Fragrance and flavor microencapsulation technology. Mater. Sci. Eng. C. 535, 440-445. https://doi.org/10. 4028/www.scientific.net/AMR.535-537.440. 